\title{
Hubungan pendidikan ibu hamil terhadap persepsi mutu pelayanan pada kunjungan pelayanan antenatal care
}

\author{
Umi Khasanah ${ }^{1 *}$ \\ ${ }^{1}$ Program Studi S1 Kebidanan, Universitas Muhammadiyah Semarang - Indonesia
}

\begin{abstract}
Integrated Antenatal Care is a comprehensive and quality antenatal service for all pregnant women provided by trained and professional medical personnel. Providing quality services and services needed by pregnant women will make the perception of pregnant women about Antenatal Care services better. The purpose of this study was to analyze the relationship of education of pregnant women to the perception of service quality at Antenatal Care service visits in the Surakarta Region Health Center. This quantitative research method use a cross sectional approach with accidental sampling technique in sampling so that as many as 108 respondents obtained then the data analysis uses chi-square. The results of this study most of the highly educated pregnant women expressed a good perception about the quality of Antenatal Care services in the Surakarta Region Health Center. The conclusion of the study is that there is a relationship between the level of education of pregnant women with the perception of service quality at Antenatal Care visits with a p-value of 0.027 . The $p$-value is smaller than $0.05(0.027$ $<0.05$ ). Improving the level of education in the community needs to be done so that pregnant women are more understanding and critical about services provided during Antenatal Care visits.
\end{abstract}

Keywords: education; perception; antenatal care

Antenatal Care terpadu merupakan pelayanan antenatal komprehensif dan berkualitas untuk semua ibu hamil yang diberikan oleh tenaga medis terlatih dan profesional. Memberikan pelayanan yang bermutu dan pelayanan yang dibutuhkan ibu hamil akan menjadikan persepsi ibu hamil tentang pelayanan Antenatal Care lebih baik. Tujuan dari penelitian ini adalah untuk menganalisi hubungan pendidikan ibu hamil terhadap persepsi mutu pelayanan pada kunjungan pelayanan Antenatal Care di Puskesmas Wilayah Surakarta. Metode penelitian kuantitatif ini menggunakan pendekatan cross sectional dengan teknik accidental sampling dalam pengambilan sampel sehingga didapatkan sebanyak 108 responden kemudian analisis data menggunakan chi-square. Hasil penelitian ini sebagian besar ibu hamil berpendidikan tinggi menyatakan persepsi yang baik tentang mutu pelayanan Antenatal Care di Puskesmas Wilayah Surakarta. Kesimpulan dari penelitian adalah ada hubungan tingkat pendidikan ibu hamil terhadap persepsi mutu pelayanan pada kunjungan Antenatal Care dengan nilai p-value 0,027. Nilai p-value lebih kecil dari $0,05(0,027<0,05)$. Meningkatkan tingkat pendidikan di masyarakat perlu dilakukan agar ibu hamil lebih paham dan kritis terkait pelayanan yang diberikan saat kunjungan Antenatal Care.

Kata Kunci: pendidikan; persepsi; antenatal care

*Korespondensi Penulis: Umi Khasanah (email: umikhasanah@unimus.ac.id), Jl. Kedungmundu No. 18, Kedungmundu, Tembalang, Semarang, Jawa Tengah 50273. 


\section{Pendahuluan}

Di Indonesia, setiap tahunnya terdapat hampir 20.000 kejadian kematian ibu akibat komplikasi pada saat hamil maupun melahirkan. Berdasarkan target MDGs tahun 2015 AKI di Indonesia masih belum mencapai target yaitu sebesar 102 per 100.000 kelahiran hidup. Pentingnya kunjungan Antenatal Care di Indonesia belum menjadi prioritas utama bagi sebagian ibu hamil di masa kehamilannya. Untuk itu perlu diketahui kaitan pendidikan ibu hamil dengan persepsi mutu pelayanan pada kunjungan Antenatal Care (Badan Pusat Statistik et al. 2013; Kementerian Kesehatan Rl, 2014).

Mutu pelayanan kesehatan menurut Azrul Azwar dan Mary R. Zimmerman 1996 adalah pelayanan kesehatan yang dapat memuaskan melalui peningkatan yang berkelanjutan terhadap pemakai jasa atau pelanggan dalam penyelenggaraannya sesuai dengan standard dan kode etik profesi (Sastrianegara, 2014).

Persepsi adalah interpretasi kombinasi pengamatan meliputi penglihatan, penciuman, pendengaran serta pengalaman masa lalu terhadap jasa oleh individu berupa proses pengenalan atau pemberian arti dan makna ke stimulus pada lingkungan oleh individu (Notoatmodjo, 2014; Supranto, 2011; Tjptono \& Chandra, 2011). Persepsi di sisi lain lebih spesifik karena seseorang dengan mudah mengobjektifikasi dan mendeskripsikan dengan caranya yang lebih ringkas (Papanikolaou \& Zygiaris, 2014).

Masalah kesehatan ibu dan perinatal merupakan masalah nasional yang perlu mendapat prioritas utama karena sangat menentukan kualitas sumber daya manusia pada generasi mendatang. Adanya faktor yang menjadikan pe- nyebab keadaan tersebut diantaranya minimnya pengetahuan tentang risiko kehamilan yang diakibatkan karena rendahnya tingkat pendidikan (Erlina et al., 2013). Dalam perkembangan masyarakat yang semakin kritis dalam berpikir dan menilai, mutu pelayanan juga menjadi sorotan berdasarkan persepsi mereka apalagi untuk pelayanan sekarang ini terutama untuk pelayanan medis (Azwar, 2010).

Ada tiga faktor tahapan persepsi yakni pemersepsi, situasi dan target. Ketiga hal tersebut dipengaruhi faktor karakteristik seperti pendidikan (Supranto, 2011). Meningkatkan tingkat pendidikan di masyarakat adalah hal penting yang perlu dilakukan, sehingga ibu hamil bisa menjadi lebih kritis terhadap pelayanan atau pemeriksaan yang mereka terima saat ANC (Jallow et al., 2012).

Antenatal Care terpadu merupakan salah satu program kunci dalam penapisan pelayanan KIA, dimulai saat hamil sampai pasca nifas. Pelayanan Antenatal Care sangat penting bagi ibu hamil karena bertujuan untuk mencegah terjadinya komplikasi pada masa kehamilan dan pascapersalinan (Mikrajab \& Rachmawati, 2016). Antenatal Care adalah pelayanan komprehensif dan berkualitas untuk semua ibu hamil yang diberikan oleh tenaga medis terlatih dan profesional. Tujuan dari pelayanan Antenatal Care adalah mempersiapkan persalinan dan kelahiran dengan preventif, mendeteksi dan mengatasi masalah masalah kesehatan selama kehamilan.

Standar minimal pelayanan Antenatal meliputi "10T", yang terdiri dari: 1) Timbang berat badan; 2) Ukur tekanan darah; 3) Ukur lingkar lengan atas; 4) Ukur tinggi fundus uteri; 5) Presentasi janin dan DJJ; 6) Pemberian imunisasi TT (Tetanus Toksoid); 7) Pemberian tablet zat 
besi minimal 90 tablet selama hamil; 8) Test laboratorium (rutin dan khusus); 9) Tatalaksana kasus; 10) Temu wicara/konseling.

Pemeriksaan selanjutnya dilakukan pmeriksaan kehamilan mulai dari anamnesa, pemeriksaan fisik, diagnosa, terapi, dan rujuk bila diperlukan (Permenkes, 2016).

Jallow et al., 2012 dalam penelitiannya yang berjudul "Women's perception of antenatal care services in public and private clinics in the Gambia" menemukan hasil bahwa Tingkat kepuasan pada layanan Antenatal adalah 79,9\% untuk fasilitas umum dan $97,9 \%$ untuk fasilitas pribadi. Persepsi buruk wanita hamil pada ANC di fasilitas umum yakni meliputi privasi dan ruang yang tidak memadai, serta kerapian dan komunikasi yang tidak memadai dengan penyedia layanan.

Penelitian Andersson et al., (2012) yang menyatakan Munculnya kelompok Antenatal adalah untuk membantu mereka mempersiapkan diri untuk melahirkan tetapi tidak untuk persiapan menjadi orang tua.

Berdasarkan penelitian yang telah dilakukan sebelumnya dapat disimpulkan bahwa mengetahui persepsi ibu hamil yang melakukan kunjungan ANC itu perlu dilakukan sehingga diketahui kepuasan saat menerima pelayanan ANC dan dapat dilakukan perbaikan pelayanan menjadi lebih baik. Perbedaan penelitian ini dengan penelitian sebelumnya adalah pada teknik pengambilan sampel, jumlah sampel, pengaturan tempat dan instrumen yang digunakan. Untuk standart minimal pelayanan ANC menggunakan standart terbaru yakni 10T berbeda dengan standart sebelumnya sehingga pelayanan ANC lebih menyeluruh dan berkualitas.
Pelayanan Antenatal Care selain kebutuhan fisik, ibu hamil juga memerlukan dukungan dan informasi tentang kehamilan dan masalah persalinan yang sering terjadi sehingga mereka memerlukan banyak diskusi tentang informasi tersebut. Dalam hal ini, bidan atau tenaga kesehatan yang terkait didorong untuk lebih banyak berkomunikasi dan lebih teliti tentang kebutuhan ibu hamil (Andersson et al., 2012).

\section{Metode}

Penelitian ini adalah penelitian kuantitatif dengan menggunakan pendekatan Cross Sectional. Penelitian dilakukan pada bulan September 2017 di Puskesmas Wilayah Surakarta dengan total 108 responden yang diambil menggunakan accidental sampling. Data diolah menggunakan analisis univariat dan bivariat. Analisis data menggunakan Chi-square untuk mengetahui ada atau tidaknya hubungan antara variabel.

\section{Hasil dan Pembahasan}

Berdasarkan Tabel 1 hasil analisis hubungan pendidikan ibu hamil terhadap persepsi mutu pelayanan Antenatal Care di Puskesmas Wilayah Surakarta diperoleh responden yang memiliki pendidikan tinggi sebanyak 24 orang dengan perincian sebanyak 10 orang menyatakan persepsi tidak baik dan 14 orang menyatakan persepsi baik terkait mutu pelayanan Antenatal Care di Puskesmas. Responden yang memiliki pendidikan rendah menyatakan persepsi tidak baik sebanyak 56 orang sedangkan yang menyatakan persepsi baik dengan pendidikan rendah sebanyak 28 orang.

Hasil uji statistik didapatkan nilai P-value $<0,05$ yakni sebesar 0,027 sehingga dapat disimpulkan 
adanya hubungan tingkat pendidikan ibu hamil terhadap persepsi mutu pelayanan pada kunjungan Antenatal Care di Puskesmas Wilayah Surakarta.

Ibu hamil di Puskesmas Wilayah Surakarta yang memiliki pendidikan tinggi sebagian besar menyatakan persepsi baik tentang mutu pelayanan Antenatal Care. Ibu hamil yang berpendidikan tinggi lebih banyak wawasan terkait kehamilan sehingga mereka lebih peduli terkait kehamilannya dan segera mungkin mengunjungi pelayanan Antenatal Care di Puskesmas. Sehingga tingkat kunjungan Antenatal Care ibu hamil yang berpendidikan tinggi lebih teratur dan lebih banyak tahu tentang mutu pelayanan Antenatal care di Puskesmas tersebut.

Ibu hamil dengan pendidikan tinggi lebih mungkin mendaftar untuk pemeriksaan kehamilan sebelum usia kehamilan 20 minggu dibandingkan dengan wanita yang tidak memiliki pendidikan tinggi (Jallow et al., 2012), pendidikan terbukti meningkatkan kesadaran (Mbachu et al., 2017) dan mereka lebih mempunyai kesadaran manfaat dari ketepatan waktu dalam melakukan kunjungan Antenatal Care (Tenkorang, 2016). Pelayanan Antenatal Care adalah titik awal untuk intervensi perawatan kesehatan ibu hamil karena menawarkan pelayanan yang preventif, kuratif dan mempersiapkan ibu untuk mengenali komplikasi kehamilan serta mencari pertolongan sejak dini (Ekott et al., 2013). Tingkat pendidikan dan pengetahuan mempengaruhi wanita dalam menyatakan persepsi terhadap pelayanan yang diterimanya. Ibu hamil dengan pendidikan tinggi lebih kritis dan menyadari waktu itu sebagai konsekuensi dari tuntutan pekerjaan (Nwaeze et al., 2013).

Responden yang memiliki pendidikan rendah sebagian besar menyatakan persepsi yang tidak baik. Ibu hamil berpendidikan rendah memiliki pengetahuan yang kurang terkait kehamilan dan mutu pelayanan di Puskesmas sehingga mutu pelayanan Puskesmas yang sudah ditingkatkan, masih dianggap kurang baik atau tidak dilakukan dengan baik. Apalagi kunjungan Antenatal Care ibu hamil berpendidikan rendah sebagian besar tidak teratur seperti yang disarankan tenaga kesehatan Puskesmas.

Tingkat pendidikan mempengaruhi penilaian persepsi ibu hamil terhadap tempat pelayanan Antenatal Care (Nwaeze et al., 2013). Rendahnya tingkat pendidikan mengakibatkan pengetahuan tentang kehamilan atau kelainan-kelainan dalam kehamilan kurang diperhatikan. Pada akhirnya dapat membawa resiko yang tidak diinginkan dan banyak menimbulkan adanya kematian baik

Tabel 1. Hubungan Pendidikan Ibu Hamil terhadap Persepsi Mutu Pelayanan Antenatal Care di Puskesmas Wilayah Surakarta Tahun 2017

\begin{tabular}{|c|c|c|c|c|c|c|c|}
\hline \multirow{4}{*}{ Umur } & \multicolumn{4}{|c|}{ Ibu yang Memilih Kontrasepsi } & \multirow{3}{*}{\multicolumn{2}{|c|}{ Total }} & \multirow{4}{*}{$P$-value } \\
\hline & & & & & & & \\
\hline & \multicolumn{2}{|c|}{ Tidak baik } & \multicolumn{2}{|c|}{ Baik } & & & \\
\hline & $\mathrm{F}$ & $\%$ & $\mathrm{~F}$ & $\%$ & $f$ & $\%$ & \\
\hline Tinggi & 10 & 41,7 & 14 & 58,3 & 24 & 100 & \\
\hline Rendah & 56 & 66,7 & 28 & 33,3 & 84 & 100 & 0,027 \\
\hline Jumlah & 66 & 61,1 & 42 & 38,9 & 108 & 100 & \\
\hline
\end{tabular}


ibu maupun bayi yang dilahirkan atau bahkan kedua-duanya. Rendahnya pendidikan ibu hamil menjadikan rendahnya pengetahuan ibu hamil. Masalah kesehatan ibu dan perinatal merupakan masalah nasional yang perlu mendapat prioritas utama karena sangat menentukan kualitas sumber daya manusia pada generasi mendatang. Adanya faktor yang menjadikan penyebab keadaan tersebut diantaranya minimnya pengetahuan tentang risiko kehamilan yang diakibatkan karena rendahnya tingkat pendidikan (Erlina et al., 2013). Mengetahui latar belakang pendidikan dari seorang ibu hamil, persepsi dan kebutuhannya terkait dengan pelayanan, dapat dianggap sebagai strategi penting untuk perencanaan perawatan (Prudêncio \& Mamede, 2018). Mengetahui persepsi pasien ANC diperlukan karena hal tersebut akan mempengaruhi kepuasan pasien terhadap harapannya pada pelayanan (Onyeajam et al., 2018).

Meningkatkan tingkat pendidikan di masyarakat adalah hal penting yang perlu dilakukan, sehingga ibu hamil bisa menjadi lebih kritis terhadap pelayanan atau pemeriksaan yang mereka terima saat ANC (Jallow et al., 2012). Selain itu, pendidikan tinggi penting berdampak terhadap sosial dan ekonomi di masyarakat (Akareem \& Hossain, 2016). Pendidikan adalah kunci untuk mengembangkan dan mengubah metode dan kualitas layanan kesehatan (Cusack \& O'Donoghue, 2012).

\section{Kesimpulan}

Responden terbanyak adalah ibu hamil dengan pendidikan rendah (SD-SMA) sebanyak 84 orang sedangkan 24 orang lulusan dari perguruan tinggi. Sebagian besar persepsi ibu hamil tentang mutu pelayanan Antenatal Care di Puskesmas Wilayah Surakarta adalah tidak baik sebanyak $61,1 \%$. Sebagian besar ibu hamil berpendidikan tinggi sebanyak 14 orang menyatakan persepsi yang baik tentang mutu pelayanan Antenatal Care di Puskesmas Wilayah Surakarta. Ada hubungan tingkat pendidikan ibu hamil terhadap persepsi mutu pelayanan kunjungan Antenatal Care di Puskesmas Wilayah Surakarta dengan p-value 0,027.[]

\section{Daftar Pustaka}

Akareem, H. S., \& Hossain, S. S. (2016). Determinants of education quality: What makes students' perception different? Open Review of Educational Research, 3(1), 52-67. https://doi.org/10.1080/23265507.2016.115 5167

Andersson, E., Christensson, K., \& Hildingsson, I. (2012). Parents' experiences and perceptions of group-based antenatal care in four clinics in Sweden. Midwifery, 28(4), 502-508. https://doi.org/10.1016/j.midw.2011.07.006

Azwar, A. (2010). Pengantar administrasi kesehatan (3 ed.). Jakarta: Binarupa Aksara Publisher.

Badan Pusat Statistik; Badan Koordinasi Keluarga Berencanan Nasional; Departemen Kesehatan; Macro International. (2013). Survei Demografi dan Kesehatan Indonesia 2012.

Cusack, T., \& O'Donoghue, G. (2012). The introduction of an interprofessional education module: Students' perceptions. Quality in Primary Care, 20(3), 231-238.

Ekott, M. I., Ovwigho, U., Ehigiegba, A., Fajola, A., \& Fakunle, B. (2013). Perception of pregnant women about antenatal care in a Cottage Hospital in Port Harcourt, Nigeria. Journal of Community Health, 38(2), 360-365. https://doi.org/10.1007/s10900-012-9625-1 
Erlina, R., Larasati, T. A., \& Kurniawan, B. (2013). Faktor-faktor yang mempengaruhi ibu hamil terhadap kunjungan pemeriksaan kehamilan di Puskesmas rawat inap Panjang Bandar Lampung. Majority: Medical Journal of Lampung University, 2(4), 29-34.

Jallow, I. K., Chou, Y. J., Liu, T. L., \& Huang, N. (2012). Women's perception of antenatal care services in public and private clinics in the Gambia. International Journal for Quality in Health Care, 24(6), 595-600. https://doi.org/ 10.1093/intghc/mzs033

Kementerian Kesehatan RI. (2014). Profil Kesehatan Indonesia Tahun 2013.

Mbachu, C., Dim, C., \& Ezeoke, U. (2017). Effects of peer health education on perception and practice of screening for cervical cancer among urban residential women in southeast Nigeria: A before and after study. BMC Women's Health, 17(1), 41-48. https:// doi.org/10.1186/s12905-017-0399-6

Mikrajab, M. A., \& Rachmawati, T. (2016). Policy Analysis of Integrated Antenatal Care implementation at Public Health Centers in Blitar City. Buletin Penelitian Sistem Kesehatan, 19(1), 41-53. https://doi.org/ 10.22435/hsr.v19i1.4988.41-53

Notoatmodjo, S. (2014). IImu Perilaku Kesehatan (2 ed.). Jakarta: Rineka Cipta.

Nwaeze, I. L., Enabor, O. O., Oluwasola, T. A. O., \& Aimakhu, C. O. (2013). Perception and satisfaction with quality of antenatal care services among pregnant women at the university college hospital, Ibadan, Nigeria.
Annals of Ibadan postgraduate medicine, 11(1), 22-28.

Onyeajam, D. J., Xirasagar, S., Khan, M. M., Hardin, J. W., \& Odutolu, O. (2018). Antenatal care satisfaction in a developing country: a crosssectional study from Nigeria. BMC Public Health, 18(1), 368-376. https://doi.org/ 10.1186/s12889-018-5285-0

Papanikolaou, V., \& Zygiaris, S. (2014). Service quality perceptions in primary health care centres in Greece. Health Expectations, 17(2), 197-207. https://doi.org/10.1111/j.1369-

7625.2011.00747.x

Permenkes. (2016). Peraturan Menteri Kesehatan RI No 43 Tahun 2016 tentang Standar Pelayanan Minimal Bidang Kesehatan.

Prudêncio, P. S., \& Mamede, F. V. (2018). Avaliação do cuidado pré-natal na atenção primária a saúde na percepção da gestante. Revista Gaúcha de Enfermagem, 39, e20180077. https://doi.org/10.1590/19831447.2018.20180077

Sastrianegara, M. F. (2014). Organisasi dan manajemen pelayanan kesehatan. Jakarta: Salemba Medika.

Supranto, J. (2011). Pengukuran tingkat kepuasan pelanggan (4 ed.). Jakarta: Rineka Cipta.

Tenkorang, E. Y. (2016). Type of health facility and utilization of antenatal care services among Ghanaian women. Population Research and Policy Review, 35(5), 631-650. https:// doi.org/10.1007/s11113-016-9406-0

Tjptono, F., \& Chandra, G. (2011). Service, quality and satisfaction (3 ed.). Yogyakarta: Andi. 